\title{
Effect of Body mass index on clinical assessment of synovitis in rheumatoid arthritis patients: comparison with musculoskeletal ultrasonography
}

\author{
A.I.Fouda, Y.A.Abdel-Hamed, W.A.Salaheldeen and R.S.El-Morsy
}

Rheumatology, Rehabilitation and Physical medicine, Dept., Faculty of Medicine, Benha Univ., Benha, Egypt E-mail:

\begin{abstract}
Rheumatoid arthritis (RA) is the most prominent systemic autoimmune rheumatic disease that may affect different tissues and organs, although the synovial joints represent the major target, The aim of this study is to assess the effect of BMI on rheumatoid arthritis disease activity and evaluate the differnce between clinical and ultrasound assessment of the Disease Activity Score in 28 joints ( $\triangle \mathrm{DAS} 28$ ) in 3 BMI subgroups according to the WHO classification. Methods: A cross-sectional study was conducted on 52 randomly selected, age \& sex matched RA patients diagnosed according to ACR/EULAR 2010 classification criteria of RA, All patients was subjected to full history taking, complete clinical examination, laboratory assessment and Musculoskeletal Ultrasonography. Results and conclusion: Effect of BMI on the disease activity of RA; clinically: there were no significant difference in DAS28 between the normal weight, overweight, and obese patients. But there was a significant difference in swollen joint count between the three BMI groups. Comparison between clinical assessment and musculoskeletal ultrasonography in the three BMI groups ; Musculoskeletal ultrasound is better than clinical examination to detect synovitis in all BMI groups. There were significant differences between swollen joint count and grey scale in normal weight, overweight and obese patients. $\mathrm{P}$ value $=0.025,<0.001$ and 0.003 respectively. Musculoskeletal ultrasound is better than clinical assessment to detect the disease activity score in 28 joints (DAS 28) in overweight and obese patients.
\end{abstract}

Keywords: Body mass index, Synovitis, Rheumatoid arthritis, Musculoskeletal, Ultrasonography.

\section{Introduction}

Rheumatoid arthritis (RA) is the most prominent systemic autoimmune rheumatic disease that may affect different tissues and organs, although the synovial joints represent the major target [1].

Body mass index (BMI) is a person's weight in kilograms divided by the square of height in meters. The standard weight status categories associated with $\mathrm{BMI}$ ranges for adults are:

- Category (A) underweight (BMI $<18.5 \mathrm{~kg} / \mathrm{m} 2)$.

- Category (B) normal weight (BMI 18.5-24.9 $\mathrm{kg} / \mathrm{m} 2)$.

- Category (C) overweigt (BMI 25- $29.9 \mathrm{~kg} / \mathrm{m} 2)$.

- Category (D) obese (BMI $\geq 30 \mathrm{~kg} / \mathrm{m} 2)$.

Body mass index (BMI) might affect rheumatoid arthritis (RA) outcomes. Clinical assessment of swollen joint count (SJC) might also be affected by obesity in terms of obesity-related excess adipose tissue [2].

Obesity, defined by body mass index (BMI) $\geq 30$ $\mathrm{kg} / \mathrm{m} 2$, is a frequent medical condition, with increased prevalence worldwide. Adipose tissue can have immune effects on most of organs through the secretion of adipocytokines. This pro-inflammatory condition may contribute to the pathogenesis of inflammatory conditions such as RA. [3]

Obesity is associated in some studies with an increased risk of RA. The prevalence of obesity in RA patients ranges from 18 to $31 \%$ previous study showed that obesity might have a structural protective impact. obesity could also be associated with severe functional and pain outcomes. [4]

Obesity might affect the assessment of RA disease activity. In light of the association of excess adipose tissue and pain score in obese patients, the clinical assessment of swollen joint count(SJC) and RA disease activity measurement might also be affected by obesity. Indeed, periarticular adiposity in obese patients might simulate clinical synovitis, thereby increasing SJC and intensifying treatments. [5]

To assess objectively the RA synovitis, imaging procedures such as ultrasonography (US) or magnetic resonance imaging (MRI) are currently recommended. Previous studies involving US have demonstrated subclinical joint inflammation in RA leading to increased risk of erosion progression. [6]

It was demonstrated that US had a better reproducibility that clinical exam. As a consequence, the DAS28 determined by clinical SJC or by US can be different. [7]

The aim of this study is to assess the effect of BMI on rheumatoid arthritis disease activity and evaluate the differnce between clinical and ultrasound assessment of the Disease Activity Score in 28 joints ( $\triangle \mathrm{DAS} 28)$ in $3 \mathrm{BMI}$ subgroups according to the WHO classification.

\section{Patients and methods}

A cross-sectional study was conducted on 52 randomly selected, age \& sex matched RA patients diagnosed according to ACR/EULAR 2010 classification criteria of RA [8].They were selected from rheumatology, rehabilitation and physical medicine department at Benha University Hospital. These patients subdivided into 3 groups according to their body mass index (BMI). 
- Group (A) normal weight (BMI 18.5-24.9 $\mathrm{kg} / \mathrm{m} 2$ ) RA patients.

- Group (B) overweigt (BMI 25- $29.9 \mathrm{~kg} / \mathrm{m} 2)$ RA patients.

- Group (C) obese (BMI $\geq 30 \mathrm{~kg} / \mathrm{m} 2)$ RA paients.

\subsection{The following patients were excluded from the} study

- Patients younger than 16 years.

- Under weight Patients with BMI<18.5

- Patients previously diagnosed with associated metabolic diseases and endocrinal abnormalities.

- Patients previously diagnosed with crystal induced arthropathy.

- Patients with advanced decompensated liver disease.

- Patients having a history of Joint trauma.

The 2010 American College of Rheumatology/European League against Rheumatism classification criteria for rheumatoid arthritis: This classification establishes a point value between 0 and 10. Every patient with a point total of 6 or higher is unequivocally classified as an RA patient. [8]

All patients was subjected to full history taking, complete clinical examination and Assessment of Body Mass Index (BMI): BMI was calculated as weight in kilograms divided by height in square meters. $\mathrm{BMI}=$ weight $(\mathrm{kg}) /$ height $(\mathrm{m} 2)$.

\subsection{Laboratory investigations}

Patients were subjected to the following investigations at the laboratories of Clinical and Chemical Pathology Department, Faculty of Medicine, Benha University Hospitals.

- Complete blood count (CBC)

- Erythrocyte sedimentation rate (ESR)

- Rheumatoid Factor (RF)

- Liver function tests: Alanine transaminase (ALT) and Aspartate transaminase (AST). Serum albumin, alkaline phosphatase (ALP), total bilirubin levels, prothrombin time.

- Serum creatinine

- Anti-cyclic citrullinated peptide (Anti-CCP) was performed by ELISA technique.

\subsection{Musculoskeletal Ultrasonography (MSUS)}

US assessment of the examined joints was performed based on the EULAR Guidelines for musculoskeletal ultrasound in rheumatology within the same day of clinical examination [9].

\subsection{Statistical analysis}

The collected data were summarized in terms of mean \pm Standard Deviation (SD) and range for quantitative data and frequency and percentage for qualitative data. Comparisons between the different study groups were carried out using the Student t-test (t) to compare means of three groups regarding parametric data. The Chi-square $\left(\begin{array}{ll}\chi & 2\end{array}\right)$ test and Fisher's Exact Test (FET) were used to compare proportions as appropriate. Comparisons between two proportions were carried out using the test of proportion (Z-test). The Pearson correlation coefficient (r) was used test for the correlation between estimated parameters. Receiver Operator Characteristic (ROC) analysis was carried out for potential diagnostic variables and the Sensitivity, Specificity, Positive Predictive Value (PPV), Negative Predictive Value (NPV) and the Area Under the Curve (AUC) were estimated. After the calculation of each of the test statistics, the corresponding distribution tables were consulted to get the "P" (probability value). Statistical significance was accepted at $\mathrm{P}$ value $<0.05(\mathrm{~S}), \mathrm{P}$ value $<0.001$ was considered highly significant (HS) while a $\mathrm{P}$ value $>0.05$ was considered nonsignificant.

\section{Results}

Our study included 52 rheumatoid arthritis (RA) patients diagnosed according to ACR/EULAR 2010 classification criteria of RA. These patients subdivided into 3 groups according to their body mass index (BMI). They were selected from rheumatology, rehabilitation and physical medicine department at Benha University Hospital.

All the patients in the study groups were subjected to history taking, physical examination, laboratory investigation, and musculoskeletal ultrasonography.

Group (A):Nineteen normal weight RA patients their weight ranged from $56.0-68.0 \mathrm{~kg}$ (Mean \pm SD $62.89 \pm 3.81)$ and their height ranged from 158.0 $170.0 \mathrm{~cm}$ (Mean \pm SD $164.26 \pm 4.36$ ). Their BMI ranged from $21.80-24.80 \mathrm{~kg} / \mathrm{m} 2$ (Mean \pm SD 23.30 $\pm 0.97)$. The patients were 18 females and 1 male and their ages ranged from 22 to 57 years (Mean \pm SD $43.0 \pm 8.89)$

Group (B):Twenty two overweight RA patients their weight ranged from $72.0-84.0 \mathrm{~kg}$ (Mean \pm SD $77.59 \pm 3.29)$ and their height ranged from $163.0-$ $171.0 \mathrm{~cm}$ (Mean \pm SD $166.41 \pm 2.13$ ). Their BMI ranged from $25.90-29.40 \mathrm{~kg} / \mathrm{m} 2$ (Mean \pm SD 28.02 $\pm 1.05)$. The patients were 20 females and 2 male and their ages ranged from 23 to 57 years (Mean \pm SD $44.41 \pm 9.25)$

Group (C):Eleven obese RA patients their weight ranged from $84.0-95.0 \mathrm{~kg}$ (Mean \pm SD $89.45 \pm$ 3.72 ) and their height ranged from $163.0-168.0 \mathrm{~cm}$ (Mean \pm SD $165.27 \pm 1.62$ ). Their BMI ranged from $30.90-34.90$ (Mean \pm SD $32.75 \pm 1.26$ ). The patients were totally females and their ages ranged from 22 to 56 years (Mean \pm SD $44.0 \pm 9.50)$. Tables $(1,2)$ 
Table (1) Comparison between the three studied groups according to demographic data.

\begin{tabular}{|c|c|c|c|c|c|c|c|c|}
\hline & \multicolumn{2}{|c|}{$\begin{array}{c}\text { Group A } \\
(\mathbf{n}=19)\end{array}$} & \multicolumn{2}{|c|}{$\begin{array}{c}\text { Group B } \\
(n=22)\end{array}$} & \multicolumn{2}{|c|}{$\begin{array}{c}\text { Group C } \\
(\mathbf{n}=11)\end{array}$} & \multirow[t]{2}{*}{ Test of sig. } & \multirow[t]{2}{*}{$\mathbf{p}$} \\
\hline & No. & $\%$ & No. & $\%$ & No. & $\%$ & & \\
\hline \multicolumn{9}{|l|}{$\overline{\text { Sex }}$} \\
\hline Male & 1 & 5.3 & 2 & 9.1 & 0 & 0.0 & $\chi^{2}=$ & \\
\hline Female & 18 & 94.7 & 20 & 90.9 & 11 & 100.0 & 0.899 & 0.791 \\
\hline \multicolumn{9}{|l|}{ Age (years) } \\
\hline Min. - Max. & \multirow{2}{*}{\multicolumn{2}{|c|}{$\begin{array}{l}22.0-57.0 \\
43.0 \pm 8.89\end{array}$}} & \multirow{2}{*}{\multicolumn{2}{|c|}{$23.0-57.0$}} & \multirow{2}{*}{\multicolumn{2}{|c|}{$22.0-56.0$}} & $\mathrm{~F}=$ & \multirow{2}{*}{0.884} \\
\hline Mean \pm SD. & & & & 9.25 & & & 0.123 & \\
\hline
\end{tabular}

Table (2) Comparison between the three studied groups according to anthropometric measures.

\begin{tabular}{|c|c|c|c|c|c|}
\hline Measures & $\begin{array}{c}\text { Group A } \\
(n=19)\end{array}$ & $\begin{array}{c}\text { Group B } \\
(\mathrm{n}=\mathbf{2 2})\end{array}$ & $\begin{array}{c}\text { Group C } \\
(\mathbf{n}=11)\end{array}$ & $\mathbf{F}$ & $\mathbf{p}$ \\
\hline Weight (kg) & & & & \multirow{3}{*}{$203.950^{*}$} & \multirow{3}{*}{$<0.001$} \\
\hline Min. - Max. & $56.0-68.0$ & $72.0-84.0$ & $84.0-95.0$ & & \\
\hline Mean \pm SD. & $62.89 \pm 3.81$ & $77.59 \pm 3.29$ & $89.45 \pm 3.72$ & & \\
\hline Sig. bet. grps. & \multirow{2}{*}{\multicolumn{3}{|c|}{$\mathrm{p}_{1}<0.001^{*}, \mathrm{p}_{2}<0.001^{*}, \mathrm{p}_{3}<0.001^{*}$}} & & \\
\hline Height (cm) & & & & & \\
\hline Min. - Max. & $158.0-170.0$ & $163.0-171.0$ & $163.0-168.0$ & \multirow{2}{*}{2.493} & \multirow{2}{*}{0.093} \\
\hline $\begin{array}{l}\text { Mean } \pm \text { SD. } \\
\text { BMI }\left(\mathrm{kg} / \mathbf{m}^{2}\right)\end{array}$ & $164.26 \pm 4.36$ & $166.41 \pm 2.13$ & $165.27 \pm 1.62$ & & \\
\hline Min. - Max. & $21.80-24.80$ & $25.90-29.40$ & $30.90-34.90$ & \multirow{3}{*}{$281.372^{*}$} & \multirow{3}{*}{$<\underset{*}{<0.001}$} \\
\hline Mean \pm SD. & $23.30 \pm 0.97$ & $28.02 \pm 1.05$ & $32.75 \pm 1.26$ & & \\
\hline Sig. bet. grps. & \multicolumn{3}{|c|}{$\mathrm{p}_{1}<0.001^{*}, \mathrm{p}_{2}<0.001^{*}, \mathrm{p}_{3}<0.001^{*}$} & & \\
\hline
\end{tabular}

F: F for ANOVA test, Pairwise comparison bet. each 2 groups was done using Post Hoc Test, (Tukey) $\mathrm{p}$ : $\mathrm{p}$ value for comparing between the studied groups $\mathrm{p}_{1}$ : $\mathrm{p}$ value for comparing between group $\mathrm{A}$ and group $\mathrm{B}$

$\mathrm{p}_{2}$ : $\mathrm{p}$ value for comparing between group A and group $\mathrm{C}$

$\mathrm{p}_{3}$ : $\mathrm{p}$ value for comparing between group B and group $\mathrm{C}$

*: Statistically significant at $\mathrm{p} \leq 0.05$

GS E/H: There was a significant difference between the three BMI groups as $\mathrm{p}$ value $=<0.001$, $\mathrm{p}$ value between normal weight and overweight patient was $0.001, \mathrm{p}$ value between normal weight and obese patients was $<0.001$, and $\mathrm{p}$ value between overweight and obese patients was 0.181 .

PD: There was a significant difference between the three BMI groups as $p$ value $=0.003, p$ value between normal weight and overweight patient was $0.084, \mathrm{p}$ value between normal weight and obese patients was $<0.002$, and $\mathrm{p}$ value between overweight and obese patients was 0.159

US DAS: there was no significant difference between the three BMI groups. table (2)

F: F for two way ANOVA test, Pairwise comparison bet. each 2 groups

$\mathrm{p}$ : $\mathrm{p}$ value for comparing between the studied groups $\mathrm{p}_{1}$ : $\mathrm{p}$ value for comparing between group $\mathrm{A}$ and group $\mathrm{B}$

$\mathrm{p}_{2}$ : $\mathrm{p}$ value for comparing between group $\mathrm{A}$ and group $\mathrm{C}$

$\mathrm{p}_{3}$ : $\mathrm{p}$ value for comparing between group B and group $\mathrm{C}$

*: Statistically significant at $\mathrm{p} \leq 0.05$

The previous table shows correlation between BMI in the three groups and different parameters in each group: There was significant correlation between SJC and BMI in the three groups (group A, $\mathrm{r}=-0.6, \mathrm{p}=0.004)($ group B $\mathrm{r}=0.1, \mathrm{p}=0.031)$ (group $\mathrm{C}, \mathrm{r}=-0.11, \mathrm{p}=0.041)$. There was significant correlation between GS E/ H and BMI in the three groups (group $\mathrm{A}, \mathrm{r}=-0.61, \mathrm{p}=0.005$ ) (group $\mathrm{B} \mathrm{r}=$ $0.09, \mathrm{p}=<0.021$ ) (group $\mathrm{C}, \quad=0.05, \mathrm{p}=<0.001$ ). There was significant correlation between $\mathrm{PD}$ and $\mathrm{BMI}$ in the three groups (group $\mathrm{A}, \mathrm{r}=-0.55$, $\mathrm{p}=0.014$ ) (group $\mathrm{B} \mathrm{r}=-0.09, \mathrm{p}=0.003$ ) (group $\mathrm{C}$, $=0.21, \mathrm{p}=0.043)$. There was significant correlation between US DAS and BMI in the three groups (group $\mathrm{A}, \mathrm{r}=-0.65, \mathrm{p}=0.002$ ) (group $\mathrm{B} \mathrm{r}=-0.07$, $\mathrm{p}=0.04$ ) (group $\mathrm{C},=0.3, \mathrm{p}=0.042$ ). There was significant correlation between global health assessment and BMI in the three groups (group A, r $=-0.67, \mathrm{p}=0.001$ ) (group B r=0.09, p=0.003) (group C , $=0.37, \mathrm{p}=0.004)$, table (3). 
Table (3) Comparison between the three studied groups according to GS E/H, PD, and US DAS.

\begin{tabular}{|c|c|c|c|c|c|}
\hline & $\begin{array}{c}\text { Group A } \\
(n=19)\end{array}$ & $\begin{array}{c}\text { Group B } \\
(\mathbf{n}=\mathbf{2 2})\end{array}$ & $\begin{array}{c}\text { Group C } \\
(n=11)\end{array}$ & $\begin{array}{c}\text { Test of } \\
\text { sig. }\end{array}$ & $\mathbf{p}$ \\
\hline \multicolumn{6}{|l|}{$\overline{\text { GSE/H }}$} \\
\hline Min. - Max. & $1.0-8.0$ & $3.0-10.0$ & $4.0-15.0$ & $\mathrm{E}=18657^{*}$ & $<00$ \\
\hline Mean \pm SD. & $3.21 \pm 2.35$ & $6.05 \pm 1.70$ & $8.0 \pm 3.38$ & & \\
\hline $\begin{array}{l}\text { Sig. bet. grps. } \\
\text { PD }\end{array}$ & \multicolumn{3}{|c|}{$\mathrm{p}_{1}=0.001^{*}, \mathrm{p}_{2}<0.001^{*}, \mathrm{p}_{3}=0.181$} & & \multirow{4}{*}{$0.003^{*}$} \\
\hline Min. - Max. & $1.0-6.0$ & $2.0-9.0$ & $3.0-10.0$ & $\mathrm{~F}=$ & \\
\hline Mean \pm SD. & $2.74 \pm 1.59$ & $4.05 \pm 1.79$ & $5.36 \pm 2.58$ & $6.780^{*}$ & \\
\hline $\begin{array}{l}\text { Sig. bet. grps. } \\
\text { US DAS }\end{array}$ & \multicolumn{3}{|c|}{$\mathrm{p}_{1}=0.084, \mathrm{p}_{2}=0.002^{*}, \mathrm{p}_{3}=0.159$} & & \\
\hline Min. - Max. & $2.35-5.33$ & $2.73-5.52$ & $2.99-5.74$ & $\mathrm{~F}=$ & \multirow{2}{*}{0.084} \\
\hline Mean \pm SD. & $3.55 \pm 0.95$ & $3.97 \pm 0.81$ & $4.28 \pm 0.93$ & 2.600 & \\
\hline
\end{tabular}

Table (4) Correlation between BMI and different parameters in each group.

\begin{tabular}{|c|c|c|c|c|c|c|}
\hline & \multicolumn{2}{|c|}{$\begin{array}{c}\text { Group A } \\
(n=19)\end{array}$} & \multicolumn{2}{|c|}{$\begin{array}{c}\text { Group B } \\
(n=22)\end{array}$} & \multicolumn{2}{|c|}{$\begin{array}{c}\text { Group C } \\
(\mathbf{n}=11)\end{array}$} \\
\hline & $\mathbf{r}$ & $\mathbf{P}$ & $\mathbf{r}$ & $\mathbf{p}$ & $\mathbf{r}$ & $\mathbf{P}$ \\
\hline Age (years) & -0.59 & 0.43 & 0.04 & 0.852 & -0.18 & 0.579 \\
\hline Weight (kg) & 0.52 & $0.021^{*}$ & 0.79 & $<0.001^{*}$ & 0.88 & $<0.001^{*}$ \\
\hline Height (cm) & -0.18 & 0.459 & -0.14 & 0.511 & -0.08 & 0.814 \\
\hline Disease duration (years) & -0.23 & 0.341 & 0.05 & 0.796 & 0.35 & 0.292 \\
\hline Morning stiffness (min) & -0.09 & 0.700 & 0.21 & 0.349 & 0.56 & 0.069 \\
\hline SJC & -0.63 & $0.004^{*}$ & 0.1 & $0.031^{*}$ & -0.11 & $0.041^{*}$ \\
\hline DAS28 & -0.64 & 0.4 & 0.04 & 0.32 & 0.28 & 0.24 \\
\hline ESR & -0.66 & $0.002^{*}$ & -0.02 & 0.904 & 0.23 & 0.489 \\
\hline CRP & -0.49 & $0.031^{*}$ & 0.013 & 0.954 & -0.51 & 0.102 \\
\hline $\mathbf{R F}(\mathbf{u} / \mathbf{m l})$ & -0.002 & 0.994 & 0.068 & 0.765 & 0.48 & 0.135 \\
\hline ACPA $(\mathbf{u} / \mathbf{m l})$ & 0.19 & 0.422 & -0.25 & 0.250 & -0.27 & 0.408 \\
\hline $\mathrm{Hb}(\mathrm{g} / \mathrm{dl})$ & 0.14 & 0.564 & -0.18 & 0.412 & 0.13 & 0.703 \\
\hline WBCs (per mcl) & -0.01 & 0.938 & -0.19 & 0.381 & -0.47 & 0.145 \\
\hline Platelets & -0.13 & 0.578 & -0.16 & 0.477 & -0.48 & 0.136 \\
\hline GS E/H & -0.61 & $0.005^{*}$ & -0.09 & $0.021^{*}$ & 0.05 & $<0.001^{*}$ \\
\hline PD & -0.55 & $0.014^{*}$ & -0.09 & $0.003^{*}$ & 0.21 & $0.043^{*}$ \\
\hline US DAS & -0.65 & $0.002^{*}$ & -0.07 & $0.04^{*}$ & 0.30 & $0.042^{*}$ \\
\hline Global health assessment & -0.67 & $0.001^{*}$ & 0.09 & $0.003^{*}$ & 0.37 & $0.004^{*}$ \\
\hline CST / dose & -0.56 & 0.184 & 0.25 & 0.258 & -0.052 & 0.879 \\
\hline MHAQ & -0.62 & 0.08 & -0.09 & 0.37 & 0.38 & 0.43 \\
\hline
\end{tabular}

r: Pearson coefficient $\quad *$ :Statistically significant at $\mathrm{p} \leq 0.05$

\section{Discussion}

Our study included 52 patients referred from rheumatology, rehabilitation and physical medicine department at Benha University Hospital. Provide evidence for a role of high BMI in the undervaluation of the DAS28 by using clinical assessment compared to US: (clinical vs. US) were statistically correlated with BMI. These results suggest that in RA patients with high BMI, SJC could be missed on clinical examination, leading to undervalue the DAS28.

Primary outcome: effect of BMI on the disease activity of RA; Clinically: there were no significant difference in DAS28 between the normal weight, overweight, and obese patients. $\mathrm{P}$ value $=0.702$. But there was a significant difference in swollen joint count between the three BMI groups. $\mathrm{P}$ value $=0.039$. Ultrasonography: there was no significant difference in US DAS between the three BMI groups. $\mathrm{P}$ value= 0.084 . But there were significant differences in grey scale and power Doppler between the three BMI groups. $\mathrm{P}$ value $=<0.001$ and 0.003 respectively.

Secondary outcome: comparison between clinical assessment and musculoskeletal ultrasonography in the three BMI groups ; Musculoskeletal ultrasound is better than clinical examination to detect synovitis in all BMI groups. There were significant differences between swollen joint count and grey scale in normal weight, overweight and obese patients. $\mathrm{P}$ value $=0.025$, < 0.001 and 0.003 respectively. Musculoskeletal ultrasound is better than clinical assessment to detect the disease activity score in 28 joints (DAS 28) in overweight and obese patients. There was no significant difference between DAS28 and US DAS 
in normal weight patients $\mathrm{p}$ value $=0.913$, but there were significant differences in overweight and obese patients $p$ value $=<0.001$ in both groups

Our data are in good agreement with several studies demonstrating the superiority of US assessment of SJC in RA patients [10], [11] However, in those studies, no evaluation of the influence of BMI was performed. Both [12], [13] reported higher crude mean DAS28 scores in patients in the obese category at last follow up. Other researchers [14], [15] reported no association between BMI and change in DAS28

In our study there was no significant difference in DAS28 between the normal weight, overweight, and obese patients. $P$ value $=0.702$. This agrees with [14], [15] as $p$ value $=0.68$, and 0.2 respectively but disagree with [12], [13] as p value $=0.002$, and 0.048 respectively.

In our study there was a significant difference in swollen joint count between the three BMI groups. $\mathrm{P}$ value $=0.039$. This disagreed with Goossens et al., [14] with $p$ value $p=0.73$. In our study there was no significant difference in US DAS between the three BMI groups. $\mathrm{P}$ value $=0.084$. This agrees with Goossens et al., [14] with $p$ value $=0.93$. But there were significant differences in grey scale and power Doppler between the three BMI groups. $\mathrm{P}$ value $=<0.001$ and 0.003 respectively.

In our study musculoskeletal ultrasound is better than clinical examination to detect synovitis in all BMI groups. There were significant differences between swollen joint count and grey scale in normal weight, overweight and obese patients. $\mathrm{P}$ value $=$ $0.025,<0.001$ and 0.003 respectively. This disagreed with Goossens et al., [14] as SJC was significantly higher by US than clinical examination for the overweight group $(\mathrm{p}=0.001)$ and obesity group $(\mathrm{p}=0.049$ ) but not for normal weight group $(\mathrm{p}=0.467)$.

In our study musculoskeletal ultrasound is better than clinical assessment to detect the disease activity score in 28 joints (DAS 28) in overweight and obese patients. There was no significant difference between DAS28 and US DAS in normal weight patients $p$ value $=0.913$, but there were significant differences in overweight and obese patients $p$ value $=<0.001$ in both groups. But in Goossens et al., [14], The DAS28 was higher with US than clinical examination within the overweight group only $(\mathrm{p}=0.002)$.

\section{Conclusion}

Effect of BMI on the disease activity of RA; clinically: there were no significant difference in DAS28 between the normal weight, overweight, and obese patients. But there was a significant difference in swollen joint count between the three BMI groups. Comparison between clinical assessment and musculoskeletal ultrasonography in the three BMI groups ; Musculoskeletal ultrasound is better than clinical examination to detect synovitis in all BMI groups. There were significant differences between swollen joint count and grey scale in normal weight, overweight and obese patients. Musculoskeletal ultrasound is better than clinical assessment to detect the disease activity score in 28 joints (DAS 28) in overweight and obese patients. There was no significant difference between DAS28 and US DAS in normal weight patients, but there were significant differences in overweight and obese patients.

\section{References}

[1] S. E. Gabriel and K. Michaud, "Epidemiological studies in incidence, prevalence, mortality, and comorbidity of the rheumatic diseases," Arthritis Res. Ther., vol. 11, pp. 1-16, 2009.

[2] K. F. Adams . "Overweight, obesity, and mortality in a large prospective cohort of persons 50 to 71 years old," N. Engl. J. Med., vol. 355, pp. 763-778, 2006.

[3] H. Tilg and A. R. Moschen, "Adipocytokines: mediators linking adipose tissue, inflammation and immunity," Nat. Rev. Immunol., vol. 6, pp. 772-783, 2006.

[4] J. Feng. "Body mass index and risk of rheumatoid arthritis: a meta-analysis of observational studies," Medicine (Baltimore)., vol. 95, 2016.

[5] A.Okifuji , B.D.Hare, "The association between chronic pain and obesity," J. Pain Res., vol. 8,PP. 399, 2015.

[6] V.Foltz . "Power Doppler ultrasound, but not low- field magnetic resonance imaging, predicts relapse and radiographic disease progression in rheumatoid arthritis patients with low levels of disease activity," Arthritis Rheum., vol. 64, pp. 67-76, 2012.

[7] S.Jousse-Joulin."Reproducibility of joint swelling assessment by sonography in patients with long-lasting rheumatoid arthritis (SEARepro study part II)," J. Rheumatol., vol. 37, pp. 938-945, 2010.

[8] D. Aletaha. "2010 rheumatoid arthritis classification criteria: an American College of Rheumatology/European League Against Rheumatism collaborative initiative," Arthritis Rheum., vol. 62, pp. 2569-2581, 2010.

[9] M. Backhaus . Guidelines for musculoskeletal ultrasound in rheumatology," Ann. Rheum. Dis., vol. 60, pp. 641-649, 2001.

[10]P. Zufferey . "Discordances between clinical and ultrasound measurements of disease activity among RA patients followed in real life," Jt. bone spine, vol. 87, pp. 57-62, 2020.

[11]C. Ciurtin, K. Wyszynski, R. Clarke, M. Mouyis, J. Manson, and G. Marra, "Ultrasounddetected subclinical inflammation was better reflected by the disease activity score (DAS-28) in patients with suspicion of inflammatory arthritis compared to established rheumatoid 
80 Effect of Body mass index on clinical assessment of synovitis in rheumatoid arthritis patients: comparison

arthritis," Clin. Rheumatol., vol. 35, pp. 24112419, 2016.

[12] S.Ajeganova, M. L. Andersson, I. Hafström, and B. S. Group, "Association of obesity with worse disease severity in rheumatoid arthritis as well as with comorbidities: a long- term followup from disease onset," Arthritis Care Res. (Hoboken)., vol. 65, pp. 78-87, 2013.

[13]G. Westhoff, R. Rau, and A. Zink, "Radiographic joint damage in early rheumatoid arthritis is highly dependent on body mass index," Arthritis Rheum. Off. J. Am. Coll. Rheumatol., vol. 56, pp. 3575-3582, 2007.

[14] J. Goossens, B. Coustet, E. Palazzo, P. Dieudé, and S. Ottaviani, "Overweight and obesity affect clinical assessment of synovitis in rheumatoid arthritis: comparison of ultrasonography and clinical exam," Clin Exp Rheumatol, vol. 37, pp. 49-54, 2019.

[15] M. Mirpourian, M. Salesi, H. Abdolahi, Z. Farajzadegan, and H. Karimzadeh, "The association of body mass index with disease activity and clinical response to combination therapy in patients with rheumatoid arthritis," J. Res. Med. Sci. Off. J. Isfahan Univ. Med. Sci., vol. 19, p. 509, 2014. 